\title{
Percepção da Qualidade do Ambiente Urbano nos bairros de Paranaguá- Paraná
}

Perception of Quality of Urban Environment of the districts of Paranaguá-Paraná

Percepción de la Calidad del Ambiente Urbano en los barrios de Paranaguá-Paraná

Zilma do Pilar Silvério Fonseca Professora Ensino Fundamental, Paranaguá, Brasil zilma_fonseca@hotmail.com

Emerson Luís Pawoski da Silva Mestrando em Ciência, Tecnologia e Sociedade, IFPR-Paranaguá, Brasil. emprovoski@gmail.com

Emerson Luis Tonetti

Professor Doutor, IFPR-Paranaguá, Brasil. emerson.tonetti@ifpr.edu.br 


\title{
RESUMO
}

A educação ambiental através da percepção local se apresenta como uma ação para solucionar problemas ambientais, devido a seu caráter sistêmico que atinge diversos modos de vida. Como as demais disciplinas ou conteúdos, a educação ambiental carece de muitos recursos, exigindo práticas que desenvolvam a consciência ecológica e a cidadania. O presente estudo de caso tem como objetivo verificar a percepção ambiental de alunos dos ensinos fundamentais iniciais e finais da Escola Rausis Mhel de Educação Infantil e Ensino Fundamental do município de Paranaguá no estado do Paraná, sobre os bairros que residiam. Para esse fim foram elaboradas nove questões com base em critérios que indicam a qualidade ambiental urbana com aplicação a cento e um estudantes. Alagamentos, sons intensos e odores desagradáveis não demonstraram ser grandes problemas, embora para esses dois últimos sejam apontados como causas veículos motorizados e materiais orgânico expostos, respectivamente. A presença de resíduos nas ruas é um problema que afeta pouco mais da metade dos entrevistados, enquanto a ausência ou baixa quantidade de calçadas, ciclovia ou ciclofaixas e arborização foi relatada. Os resultados destacam a importância de haver espaços livres de edificação para lazer e urgência de trajetos que permitam o transporte não motorizado, uma vez que a maioria da população local faz uso desses. A prática de percepção do bairro demonstrou ser um método capaz de fornecer conhecimento local para manutenção da qualidade ambiental.

PALAVRAS-CHAVE: Educação ambiental. Cidadania. Qualidade urbana.

\begin{abstract}
Environmental education through local perception and due its systemic aspect that affects different ways of life presents an action to solve environmental problems. As other disciplines or contents, environmental education lacks many resources and demands practices that develop ecological awareness and citizenship. The present case study aims to verify the environmental perception of students of the initial and final fundamental education of the Rausis Mhel School of Early Childhood Education and Elementary School of the city Paranaguá in the state of Paraná about the districts that they resided. For this purpose and based on criteria that indicate the urban environmental quality, nine questions were elaborated with application to one hundred and one students. Floods, intense sounds and unpleasant odors are not problems but to them were pointed the causes motor vehicles and exposed organic materials, respectively. The presence of residues in the streets is a problem that affects slightly more than half of the interviewees. The absence or low quantity of sidewalks, bicycle lanes or cycle paths and afforestation has been reported. The results highlight the importance of having free spaces for recreation and urgency of routes that allow non-motorized transportation, since most of the local population makes use of these. The practice of districts perception has proved to be a method capable of providing local knowledge to maintain environmental quality.
\end{abstract}

KEY-WORDS: Environmental education. Citizenship. Urban quality.

\section{RESUMEN}

La educación ambiental a través de la percepción local se presenta como una acción para solucionar problemas ambientales, debido a su carácter sistémico que alcanza diversos modos de vida. Como las demás disciplinas o contenidos, la educación ambiental carece de muchos recursos, exigiendo prácticas que desarrollen la conciencia ecológica y la ciudadanía. El presente estudio de caso tiene como objetivo verificar la percepción ambiental de alumnos de las enseñanzas fundamentales iniciales y finales de la Escuela Rausis Mhel de Educación Infantil y Enseñanza Fundamental del municipio de Paranaguá en el estado de Paraná, sobre los barrios que residian. A este fin se elaboraron nueve cuestiones sobre la base de criterios que indican la calidad ambiental urbana con aplicación a ciento y un estudiantes. Las inundaciones, sonidos intensos y olores desagradables no han demostrado ser grandes problemas, aunque para estos dos últimos se apuntan como causas vehículos motorizados y materiales orgánicos expuestos, respectivamente. La presencia de residuos en las calles es un problema que afecta poco más de la mitad de los entrevistados, mientras que la ausencia o baja cantidad de calzadas, ciclovía o ciclofajas y arborización fue relatada. Los resultados destacan la importancia de que haya espacios libres de edificación para ocio y urgencia de trayectos que permitan el transporte no motorizado, una vez que la mayoría de la población local hace uso de esos. La práctica de percepción del barrio demostró ser un método capaz de proporcionar conocimiento local para el mantenimiento de la calidad ambiental.

PALABRAS CLAVE: Educación ambiental. Ciudadanía. Calidad urbana. 


\section{INTRODUÇÃO}

Os problemas ambientais exigem ações que produzam efeitos positivos na edificação de uma sociedade mais sustentável, de modo que compreendam práticas mais sistematizadas entre todos os modos de intervenção ambiental direta, como as atividades de Educação Ambiental (EA) (BRASIL, 2005), desenvolvidas muitas vezes dentro da sala de aula.

Os instrumentos pedagógicos usados nesse intento mostram-se cada vez mais limitados e começam a ser questionados. Essas ações em que o educador atua no processo de ensino e aprendizagem e os educandos são indivíduos passivos, causam uma educação deficitária. Perante esse contexto, os livros didáticos são por muitas vezes o único instrumento em que os indivíduos usufruem devido à escassez de outros recursos (MELO, 2016).

A interação entre meio ambiente e a educação, para a construção da cidadania, contribui para a criação de um ambiente desafiador, requerendo com urgência novos conhecimentos para absorver sistemas sociais complicados e dessa forma, os malefícios ambientais aumentam. Segundo Loureiro (2004), a educação ambiental é definida como ato de conhecer, trabalhar e observar o ambiente, passando de uma ação teórica para uma ação complexa e fundamentada.

Diante desta perspectiva, o reconhecimento e/ou percepção da qualidade ambiental do bairro em que os estudantes residem pode ser um caminho para a construção de atividades em sala de aula que promovam a EA e, consequentemente, a cidadania.

O conceito qualidade ambiental é amplamente utilizado na literatura acadêmica, tendo inúmeras definições e interpretações. A pesquisa sobre qualidade ambiental no ambiente urbano no Brasil começou a ter destaque com a publicação do livro "Qualidade Ambiental e Adensamento Urbano" (NUCCl, 2001; 2008). Este autor estudou o distrito de Santa Cecília, no Município de São Paulo e desenvolveu um método para a avaliação da qualidade ambiental em áreas urbanas que consiste, resumidamente, na construção de uma carta síntese da qualidade ambiental urbana, baseada no levantamento e representação cartográfica por meio de critérios em escalas que valorizem o cotidiano do cidadão. Os critérios adotados foram: usos potencialmente poluidores; espaços de uso público livres de edificações; verticalidade das edificações; enchentes; densidade populacional; e cobertura vegetal. $O$ autor questiona a proposta de intensificação do uso da terra na localidade e utiliza a qualidade do ambiente como um dos critérios para restringir e prevenir as consequências geradas pelo aumento da densidade populacional e das edificações.

A metodologia proposta por Nucci (2008) é de demonstrar um gradiente de qualidade em unidades espaciais, do ambiente urbano pela avaliação das características estruturais e funcionais, sob a perspectiva dinâmica deste ambiente com a utilização de critérios e parâmetros previamente selecionados.

Essa forma de avaliação tem a potencialidade para ser utilizada em atividades de percepção do ambiente urbano, junto aos estudantes, a partir da elaboração de questões que ressaltem os critérios utilizados para a qualificação do ambiente em relação ao bairro onde residem.

Essa prática posteriormente pode ser utilizada em atividades lúdicas de EA, como os jogos e brincadeiras, estando relacionada à atividade pedagógica, principalmente no que tange a 
educação ambiental. Por esses aspectos é caracterizada como uma ferramenta motivadora para a aprendizagem, que agrega ao conhecimento, o saber e a exploração do mundo pelos alunos.

Nesse sentido, deve-se considerar que o jogo tem a eficácia de se comunicar com a realidade, inserindo o indivíduo no tema que é oferecido (BROUGÈRE, 1998) e desta maneira, reproduzindo a realidade do estudante.

Pesquisas realizadas na área urbana de Paranaguá (TONETTI, 2011, FREITAS; TONETTI, 2016) demonstraram a existência de um ambiente com baixa qualidade ambiental, associada com parâmetros negativos de critérios, como: poluição vinculada aos usos portuários e suas vias de acesso; baixa potencialidade para a mobilidade de pedestres e ciclistas, em função da qualidade e/ou ausência de calçadas e ciclovias e/ou ciclo-faixas; arborização viária reduzida ou ausente e ausência ou oferta reduzida de espaços de uso público para o lazer.

Um ambiente urbano com qualidade gera muitos benefícios físicos e psicológicos para os moradores, como a sustentabilidade e valoração local (NUCCl, 2008). Assim, a investigação da percepção de estudantes sobre a qualidade do ambiente em que residem, ou seja, do bairro, tem a potencialidade para subsidiar futuras atividades lúdicas de $E A$, sendo principalmente jogos. Estas podem reproduzir uma realidade e promover a reflexão sobre o tema, que por sua vez, podem influenciar a formação e a ação de manutenção e melhorias na condição do ambiente urbano.

As descrições dos critérios e seus respectivos parâmetros para serem utilizados na avaliação da qualidade ambiental urbana, podem ser encontrados na revisão realizada por Buccheri-Filho e Tonetti (2011).

Diante do contexto, o presente trabalho tem como objetivo investigar a percepção dos estudantes de uma escola do município de Paranaguá, no litoral do Estado do Paraná, sobre a qualidade do ambiente urbano, dos bairros em que residem, como subsídio para as atividades de Educação Ambiental.

\section{METODOLOGIA}

Este trabalho foi realizado no município de Paranaguá, estado do Paraná. A instituição observada foi a Escola Rausis Mhel de Educação Infantil e Ensino Fundamental, com alunos do 5o ao 9o ano, totalizando 7 turmas e 101 estudantes. A escola está localizada no bairro Jardim Paranaguá (Figura 1) e a maioria dos estudantes residem nos bairros do entorno. 
Figura 1 - Localização do bairro Jardim Paranaguá (número 26 na margem da PR 407), indicando a localização da escola e dos bairros próximos.
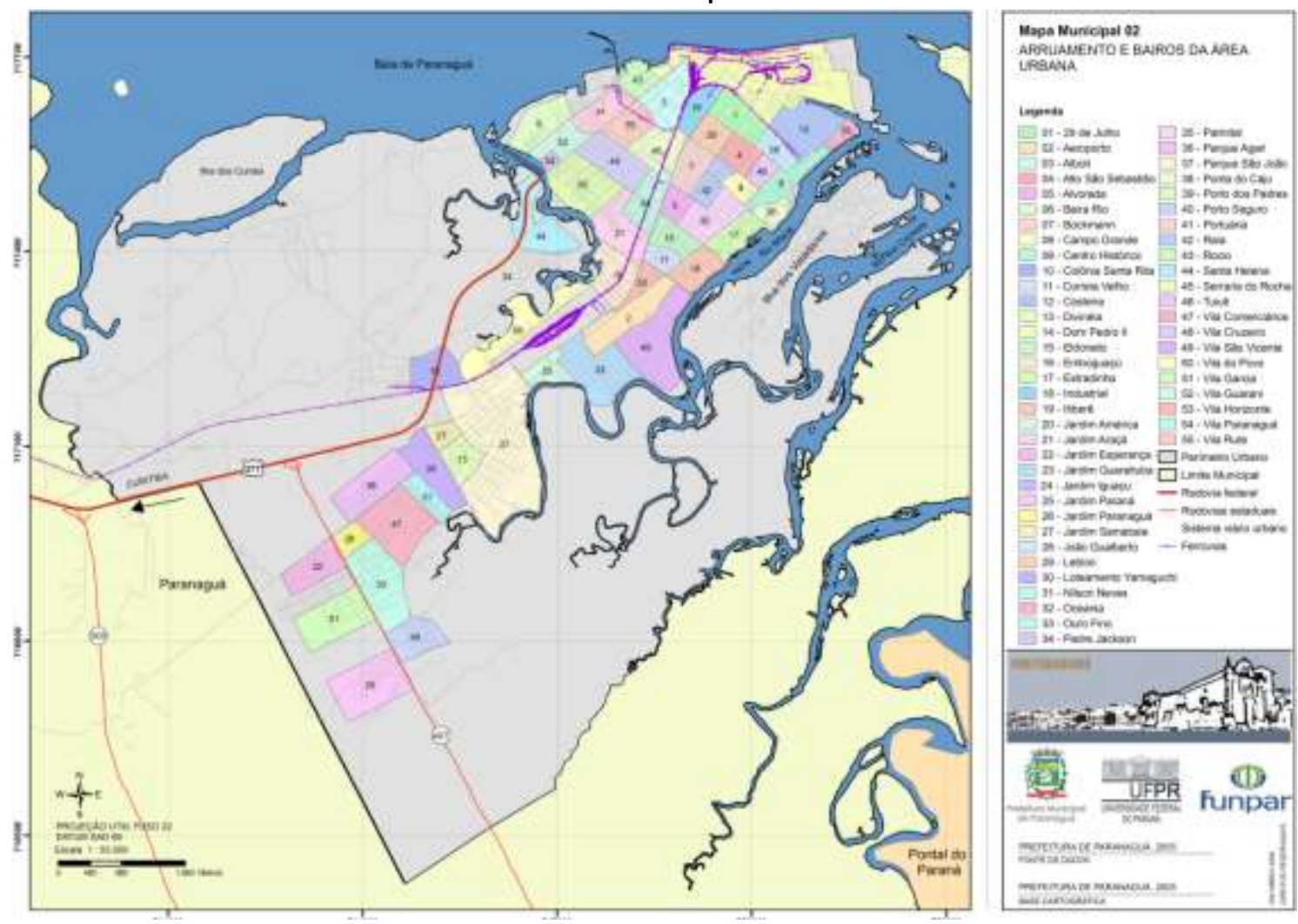

Fonte: PARANAGUÁ, 2019.

Esta escola foi selecionada para a realização da pesquisa por situar-se na região do município que está em processo de consolidação urbana e, também, de forma prática, pela facilidade de acesso dos autores.

Previamente foram selecionados, a partir da literatura específica, os seguintes critérios: poluição do ar, do solo, poluição sonora, alagamentos frequentes, qualidade da calçada e da ciclovia e/ou ciclofaixa, qualidade da arborização viária, presença e distância de área de lazer no bairro em que reside. A partir deles, foram elaboradas nove (9) questões de múltipla escolha em questionário com a possibilidade de respostas abertas, para oportunizar mais informações sobre o assunto sem prejudicar a tabulação dos dados, conforme afirmação de Marconi e Lakatos (2008).

Seguindo orientação dos referidos autores um pré-teste do questionário foi realizado no início do ano letivo de 2018, ou seja, a aplicação do questionário foi testada em uma das salas para verificar a necessidade mudanças. Constatou-se que não havia necessidades de modificações, por esse motivo, o questionário foi aplicado aos 101 alunos do ensino fundamental da escola. Para dar continuidade ao desenvolvimento da pesquisa, os dados foram tabulados em planilha específica utilizando o software Apache OpenOffice Calc 4.1.4 para este fim, facilitando o cálculo percentual para viabilizar a comparação dos mesmos e para destacar informações relevantes sobre a verificação da percepção dos alunos sobre o bairro em que residem. 0 
questionário foi avaliado a partir de uma abordagem local, considerando o contexto da proximidade da moradia de cada aluno em relação à escola. Após a aplicação verificamos que um dos estudantes não residia nas proximidades da escola sendo, por isso, excluídas suas respostas do processamento dos dados. Assim, um total de cem (100) estudantes foi investigado e a pesquisa foi desenvolvida quali-quantitativamente, a fim de investigar os significados das relações do ambiente com a sociedade na paisagem urbana.

\section{RESULTADOS E DISCUSSÃO}

O quadro de percepção da qualidade do ambiente do bairro em que residem os estudantes (Quadro 1), ou seja, na região sul da área urbana, demonstra que dos nove (9) critérios da qualidade ambiental selecionados para o destaque da qualidade do bairro, cinco (5) foram considerados negativos pelos estudantes. Estes foram os seguintes: calçada, ciclovia e/ou ciclofaixa, arborização viária, presença e distância de área de lazer no bairro em que reside. Esses resultados confirmam aqueles obtidos, com a avaliação in loco realizada por Tonetti (2011), para os mesmos critérios em bairros residenciais ao norte da área urbana de Paranaguá.

A percepção dos estudantes é positiva para o critério poluição do ar, do solo, poluição sonora e alagamentos frequentes no bairro em que residem, diferentemente, do que foi encontrado por Tonetti (2011).

Essas diferenças, possivelmente se relacionam com a presença dos usos e das vias para fins portuários, presentes na região norte da área urbana do município.

Quadro 1: Percepção da qualidade do ambiente do bairro em que residem os estudantes.

\begin{tabular}{|c|c|c|c|}
\hline Item & Questão & Resposta (\%) & Complementos* \\
\hline \multirow[t]{6}{*}{1} & $\begin{array}{c}\text { Ao andar pelo } \\
\text { bairro onde mora, } \\
\text { você sente cheiro } \\
\text { ruim: }\end{array}$ & & Possíveis fontes: \\
\hline & em todo o bairro? & 1.01 & \\
\hline & $\begin{array}{c}\text { na maior parte do } \\
\text { bairro? }\end{array}$ & 1.01 & \\
\hline & $\begin{array}{l}\text { na metade do } \\
\text { bairro? }\end{array}$ & 6.06 & Valeta \\
\hline & $\begin{array}{c}\text { em pequena parte } \\
\text { do bairro? }\end{array}$ & 33.3 & $\begin{array}{l}\text { Valeta (2), urina, } \\
\text { animais, fogo, } \\
\text { esgoto. }\end{array}$ \\
\hline & $\begin{array}{l}\text { não tem cheiro } \\
\text { ruim no bairro? }\end{array}$ & 58.6 & \\
\hline 2 & $\begin{array}{c}\text { Ao andar pelo } \\
\text { bairro onde mora, } \\
\text { o barulho } \\
\text { incomoda você: }\end{array}$ & & Possíveis fontes: \\
\hline
\end{tabular}




\begin{tabular}{|c|c|c|c|}
\hline & em todo o bairro? & 10.8 & $\begin{array}{l}\text { Carro (3), moto } \\
\text { (2), caminhão } \\
\text { (3), igreja, } \\
\text { animais (2), } \\
\text { música alta. }\end{array}$ \\
\hline & $\begin{array}{c}\text { na maior parte do } \\
\text { bairro? }\end{array}$ & 9.9 & $\begin{array}{c}\text { Bar, bicicleta } \\
\text { motorizada (2), } \\
\text { caminhão (4), } \\
\text { vizinho, carro (4), } \\
\text { moto (4). }\end{array}$ \\
\hline & $\begin{array}{l}\text { na metade do } \\
\text { bairro? }\end{array}$ & 9.9 & $\begin{array}{c}\text { Bicicleta } \\
\text { motorizada (2), } \\
\text { carro, moto (3), } \\
\text { caminhão. }\end{array}$ \\
\hline & $\begin{array}{c}\text { em pequena parte } \\
\text { do bairro? }\end{array}$ & 34.6 & $\begin{array}{c}\text { Bar (3), vizinho } \\
\text { (8), música alta } \\
\text { (4), } \\
\text { estabelecimento, } \\
\text { bicicleta } \\
\text { motorizada, } \\
\text { caminhão (4). }\end{array}$ \\
\hline & $\begin{array}{l}\text { não tem barulho } \\
\text { incômodo no } \\
\text { bairro? }\end{array}$ & 34.6 & \\
\hline 3 & $\begin{array}{l}\text { Ao andar pelo } \\
\text { bairro onde mora, } \\
\text { você observa lixo } \\
\text { jogado no solo: }\end{array}$ & & Possíveis fontes: \\
\hline & em todo o bairro? & 10.2 & $\begin{array}{c}\text { Garrafas, } \\
\text { sacolas(2), lixo } \\
\text { (2) }\end{array}$ \\
\hline & $\begin{array}{c}\text { na maior parte do } \\
\text { bairro? }\end{array}$ & 15.9 & Sacola, lixo. \\
\hline & $\begin{array}{l}\text { na metade do } \\
\text { bairro? }\end{array}$ & 14.7 & Lixo \\
\hline & $\begin{array}{c}\text { em pequena parte } \\
\text { do bairro? }\end{array}$ & 30.6 & $\begin{array}{l}\text { Lixo (2), sacola } \\
\text { (3), copo } \\
\text { descartável. }\end{array}$ \\
\hline & $\begin{array}{c}\text { não tem lixo } \\
\text { jogado pelo solo } \\
\text { do bairro? }\end{array}$ & 28.4 & \\
\hline 4 & $\begin{array}{l}\text { No bairro, quando } \\
\text { chove ocorre } \\
\text { alagamento com } \\
\text { frequência: }\end{array}$ & & \\
\hline & em todas as ruas? & 6.6 & \\
\hline & $\begin{array}{c}\text { na maior parte } \\
\text { das ruas? }\end{array}$ & 7.54 & \\
\hline
\end{tabular}




\begin{tabular}{|c|c|c|c|}
\hline & $\begin{array}{c}\text { na metade das } \\
\text { ruas? }\end{array}$ & 7.54 & \\
\hline & $\begin{array}{c}\text { em pequena parte } \\
\text { das ruas? }\end{array}$ & 32.0 & \\
\hline & $\begin{array}{l}\text { não ocorrem } \\
\text { alagamentos } \\
\text { frequentes? }\end{array}$ & 46.2 & \\
\hline \multirow[t]{6}{*}{5} & $\begin{array}{l}\text { Ao andar pelo } \\
\text { bairro onde mora, } \\
\text { as calçadas são } \\
\text { boas: }\end{array}$ & & \\
\hline & em todas as ruas? & 11.3 & \\
\hline & $\begin{array}{c}\text { na maior parte } \\
\text { das ruas? }\end{array}$ & 12.2 & \\
\hline & $\begin{array}{c}\text { na metade das } \\
\text { ruas? }\end{array}$ & 25.4 & \\
\hline & $\begin{array}{c}\text { em pequena parte } \\
\text { das ruas? }\end{array}$ & 16.9 & \\
\hline & $\begin{array}{c}\text { não tem calçadas } \\
\text { boas? }\end{array}$ & 33.9 & \\
\hline \multirow[t]{6}{*}{6} & $\begin{array}{l}\text { Ao andar pelo } \\
\text { bairro onde mora, } \\
\text { a ciclovia/ciclo } \\
\text { faixa está } \\
\text { presente: }\end{array}$ & & $\begin{array}{c}\text { Estado de } \\
\text { conservação da } \\
\text { ciclovia/ciclofaixa } \\
\text { presente: }\end{array}$ \\
\hline & em todas as ruas? & 10.3 & $\begin{array}{c}\text { Sim (8), não, } \\
\text { mais ou menos. }\end{array}$ \\
\hline & $\begin{array}{c}\text { na maior parte } \\
\text { das ruas? }\end{array}$ & 4.71 & Não, sim. \\
\hline & $\begin{array}{c}\text { na metade das } \\
\text { ruas? }\end{array}$ & 8.49 & $\operatorname{Sim}(3)$ \\
\hline & $\begin{array}{c}\text { em pequena parte } \\
\text { das ruas? }\end{array}$ & 12.2 & $\operatorname{Sim}(2)$, não \\
\hline & $\begin{array}{c}\text { não tem } \\
\text { ciclovia/ciclofaixa? }\end{array}$ & 64.1 & \\
\hline \multirow[t]{5}{*}{7} & $\begin{array}{l}\text { Ao andar pelo } \\
\text { bairro onde mora, } \\
\text { a arborização } \\
\text { viária está } \\
\text { presente: }\end{array}$ & & \\
\hline & em todas as ruas? & 2.85 & \\
\hline & $\begin{array}{c}\text { na maior parte } \\
\text { das ruas? }\end{array}$ & 7.61 & \\
\hline & $\begin{array}{c}\text { na metade das } \\
\text { ruas? }\end{array}$ & 7.61 & \\
\hline & $\begin{array}{c}\text { em pequena parte } \\
\text { das ruas? }\end{array}$ & 36.1 & \\
\hline
\end{tabular}




\begin{tabular}{|c|c|c|c|}
\hline & $\begin{array}{c}\text { não existe } \\
\text { arborização viária } \\
\text { no bairro? }\end{array}$ & 45.7 & \\
\hline \multirow[t]{6}{*}{8} & $\begin{array}{l}\text { Quantas quadras } \\
\text { você caminha } \\
\text { para chegar na } \\
\text { área de lazer mais } \\
\text { próxima: }\end{array}$ & & $\begin{array}{l}\text { Outros valores } \\
\text { respondidos: }\end{array}$ \\
\hline & 1 quadra? & 12.2 & \\
\hline & 2 quadras? & 10.3 & \\
\hline & 3 quadras? & 9.43 & \\
\hline & 4 quadras? & 18.8 & \\
\hline & $\begin{array}{c}\text { Outra quantidade. } \\
\text { Quantas? }\end{array}$ & 49.0 & $\begin{array}{c}\text { Não tem área de } \\
\text { lazer } 21,6,7 \text { (2). } \\
8 \text { quadras. }\end{array}$ \\
\hline \multirow[t]{5}{*}{9} & $\begin{array}{l}\text { No bairro onde } \\
\text { mora, tem: }\end{array}$ & & $\begin{array}{c}\text { Estado de } \\
\text { conservação dos } \\
\text { equipamentos de } \\
\text { lazer: }\end{array}$ \\
\hline & $\begin{array}{l}\text { Parquinho para } \\
\text { criança? }\end{array}$ & 9.34 & Sim (2), não (5) \\
\hline & $\begin{array}{l}\text { Campinho de } \\
\text { futebol? }\end{array}$ & 22.4 & $\begin{array}{c}\text { Sim (4), não (11), } \\
\text { mais ou menos } \\
\text { (4). }\end{array}$ \\
\hline & $\begin{array}{c}\text { Academia ao ar } \\
\text { livre? }\end{array}$ & 7.47 & Não (2). \\
\hline & $\begin{array}{c}\text { Outro } \\
\text { equipamento de } \\
\text { lazer. Qual? }\end{array}$ & 60.7 & $\begin{array}{l}\text { Não tem (65), } \\
\text { terreno baldio } \\
(2)\end{array}$ \\
\hline
\end{tabular}

Organização: os autores.

* os números indicados entre parênteses demonstram a quantidade de citações do evento.

Especificamente, nota-se que a maioria dos estudantes entrevistados (91,9\%) não sofrem, com o desconforto do mal cheiro no bairro. No entanto, alguns salientaram que são possíveis fontes de odores ruins, as valetas com esgoto a céu aberto, urina, fogo (queimadas) e animais. Em relação à poluição sonora no bairro, mais de $(65 \%)$ responderam que os barulhos não incomodam. Os demais afirmam que diferentes fontes incomodam os residentes do bairro, tais como: motos, carros, caminhões e bicicletas motorizadas.

Para a questão relacionada à poluição do solo, mediante a visualização de resíduos, $59 \%$ dos entrevistados afirmam que não há ou há em pequena parte do bairro, resíduos presentes no solo. Logo, supõe-se que os resíduos são colocados nos seus devidos lugares. E $41 \%$ dos alunos responderam que diretamente sofrem com o acúmulo de resíduos domésticos descartados nas ruas (Quadro 1). 
$\mathrm{Na}$ quarta questão tratou-se de um problema muito comum no município, o alagamento frequente. Contudo, $78,2 \%$ dos alunos que moram nas proximidades da escola, afirmaram não ter problemas de alagamentos frequentes em seus bairros.

Sobre o bom estado de conservação das calçadas nos bairros das proximidades, $76,2 \%$ dos alunos dizem não ter calçadas boas para se deslocar pela metade do bairro ou mais. Tal resultado torna-se preocupante, visto que muitos alunos deslocam-se a pé para a escola e necessitam de acessibilidade adequada.

No sexto critério avaliou-se a presença de ciclo via e/ou ciclofaixa, sendo o resultado igualmente surpreendente: $76,3 \%$ dos entrevistados responderam que não há ou há em pequena parte do bairro esse importante equipamento público que viabiliza o deslocamento não motorizado pelo bairro ou entre os bairros. Ainda, alguns relataram a presença da mesma, mas em condições precárias e muitas vezes danificadas, prejudicando o acesso dos ciclistas, os quais tendem a pedalar nas ruas junto aos carros, colocando em risco suas próprias vidas.

Quanto à precariedade da arborização viária nos bairros em Paranaguá, esta foi identificada por $81,8 \%$ dos estudantes. Tal fato coloca em evidência a falta de árvores nos bairros e consequentemente a ausência dos benefícios que elas podem proporcionar aos moradores.

Nas duas últimas questões foram destacados dois critérios importantes da qualidade do ambiente urbano para os moradores e a necessidade de percorrer longas distâncias para usufruir de um equipamento público de lazer. Houve destaque pela sua ausência em quantidade e qualidade nas proximidades das residências.

O campinho de futebol é o espaço de uso público para o lazer que está mais presente nos bairros, contudo, apenas $22,4 \%$ tiveram esta percepção.

Este resultado destaca a observação realizada por Tonetti (2011), ao constatar a concentração de espaços de uso público para o lazer, na região central da área urbana do município e na localidade conhecida como "Aeroparque". Este autor sugere a existência de áreas desprovidas de equipamentos públicos de lazer para atender em quantidade e qualidade adequadas a população. 


\section{CONSIDERAÇÕES FINAIS}

A partir dos resultados obtidos, podemos afirmar que os estudantes percebem questões relacionadas com a qualidade do ambiente urbano em que residem. Houve similaridade entre a região urbana norte e sul, em relação a certos critérios e diferenças em relação a outros. Nos bairros em que residem, a poluição não é destaque na percepção dos estudantes, mas sim a qualidade das calçadas, das ciclovias e da arborização viária. Mais notória é a percepção em relação à presença e a distância dos espaços de uso público para o lazer nos bairros em que residem.

Essa percepção da qualidade ambiental do bairro poderá ser utilizada para a elaboração de atividades de EA, principalmente, relacionada a "jogos", na tentativa de estabelecer um caminho para a construção de atividades em sala de aula que promovam a capacidade crítica e a cidadania nos estudantes.

\section{REFERÊNCIAS BIBLIOGRÁFICAS}

BRASIL. Programa Nacional de Educação Ambiental - ProNEA. 3ạ ed. Brasília: Ministério do Meio Ambiente - Diretoria de Educação Ambiental, Ministério da Educação - Coordenação Geral de Educação Ambiental, 2005. Disponível em <http://portal.mec.gov.br/secad/arquivos/pdf/educacao ambiental /pronea3.pdf>. Acesso em: 7 abr. 2017.

BROUGÈRE, G. Jogo e Educação. Trad. Patrícia Chittoni Ramos. Porto Alegre: Artes Médicas, 1998. 218 p.

BUCCHERI-FILHO, A. T.; TONETTI, E. L. Qualidade ambiental nas paisagens urbanizadas. Revista Geografar, v. 6, n. 1, p. 23 - 54, 2011. Disponível em:

<https://revistas.ufpr.br/geografar/article/view/21802/14191> , Acesso em: 16 jul. 2018.

FREITAS, K. R. de; TONETTI, E. L. Usos portuários ou correlatos na área urbana do município de Paranaguá-PR. Revista Nacional de Gerenciamento de Cidades, v. 4, n. 24, ANAP, 2016. Disponível em: <http://www.amigosdanatureza.org.br/publicacoes/index.php/gerenciamento_de_cidades/issue/view/ 130>. Acesso em: 10 abr. 2017.

LAKATOS, E. M.; MARCONI, M. de A. Fundamentos de metodologia científica. 5. ed. São Paulo: Atlas, 2008.

LOUREIRO, C.F.B. Educação Ambiental Transformadora. In: LAYRARGUES, P.P. (Org.). Identidades da Educação Ambiental Brasileira. Brasília: Ministério do Meio Ambiente, 2004, p. 65-84.

MELO, F.G. Estado e Políticas Públicas para o Livro Didático no Brasil. Revista on line de Política e Gestão Educacional, v.20, n.3, p.547-562, 2016. Disponível em:

<https://periodicos.fclar.unesp.br/rpge/article/view/9716/6423>. Acesso em: 15 jan. 2019.

NUCCI, J. C. Qualidade Ambiental e Adensamento Urbano: um estudo de ecologia e planejamento da paisagem aplicado ao distrito de Santa Cecília (MSP). São Paulo: Ed. Humanitas/FFLCH/USP, 2001. . 236 p. 
NUCCI, J. C. Qualidade Ambiental e Adensamento Urbano: um estudo de ecologia e planejamento da paisagem aplicado ao distrito de Santa Cecília (MSP). Curitiba: Edição do autor (ISBN 978-85-908251-04), 2008 ( 2 a ed.). 142p. Disponível em <www.geografia.ufpr.br/laboratorios/labs/?pg=publicacoes-php> Acesso em 15 dez. 2008.

PARANAGUÁ. Plano Diretor: Mapa Arruamento e Bairros da Área Urbana. Disponível em < http://www.paranagua.pr.gov.br/plano_diretor/+\%20PLANO\%20DIRETOR/WORD/Mapas\%20Volume\%2 0I\%20-\%20Parte\%202\%20-\%20An\%C3\%A1lise\%20Tem\%C3\%A1tica\%20e\%20Diagn\%C3\%B3stico\%20\%20Contexto\%20Municipal/Mapa\%202\%20-

\%20Arruamento\%20e\%20bairros\%20da\%20area\%20urbana.pdf> Acesso em 20 jan. 2019.

TONETTI, E. L. Potencialidades de adensamento populacional por verticalização das edificações e qualidade ambiental urbana no município de Paranaguá, Paraná, Brasil. 235f. Tese (Doutorado) - Setor de Ciências da Terra, Universidade Federal do Paraná, Curitiba. 2011. Disponível em <http://200.17.203.155/index.php?codigo_sophia=285569>. Acesso em 12 abr. 2015. 